\title{
Lessons learned from a generation of community-driven business retention and expansion programming
}

by Michael Darger, University of Minnesota Extension Center for Community Vitality 462 Coffey Hall, 1420 Eckles Ave., St. Paul, MN, 55108, darger@umn.edu

Brigid Tuck, University of Minnesota Extension Regional Office, 1961 Premier Drive, Suite 110, Mankato, MN 56001-5901

John Bennett, University of Minnesota Extension Regional Office, 179 University Road, Cloquet, MN 55720

\section{The Version of Record of this manuscript has been published and is available in Community Development, February 6, 2017, http://www.tandfonline.com/ http://dx.doi.org/10.1080/15575330.2017.1284877.}

\begin{abstract}
Business retention and expansion (BRE) can strengthen the economic and social fabrics of communities when led by a broad cross-section of community leaders and supported by professionals skilled in BRE process techniques. This article explains lessons learned from a generation of broad-based BRE visitation initiatives facilitated by the University of Minnesota Extension. Two program improvements, their genesis, and outcomes are featured. The first improvement stemmed from a comprehensive review of nine community BRE initiatives in which the results had not been reported as either successful or unsuccessful. The second improvement is the application of a consistent evaluation rubric: ripple effect mapping. The article demonstrates that 1. volunteer involvement in BRE can be effective in creating community-wide benefits and 2. there are benefits to striving for both community development and economic development through BRE. Thus BRE can be effective for community improvement overall, not just for jobs and economic impact.
\end{abstract}

Keywords: Business Retention and Expansion, BRE, Community Engagement, Ripple Effect Mapping, BRE Visitation Program 


\section{Introduction}

Business retention and expansion (BRE) is a popular economic development activity in the United States and Canada (Warner \& Zheng, 2011). The University of Minnesota's $B R \& E$ Strategies Program has operated continuously since 1990 and thus offers experience from more than 75 community-driven BRE initiatives in that time period. The thesis of this article is that BRE can strengthen the economic and social fabrics of communities when led by a broad crosssection of community leaders and supported by educators who are familiar with BRE techniques. This article provides ample evidence to support the thesis and lessons learned from a generation of BRE efforts in Minnesota.

There is no standard definition of business retention and expansion. Even Business Retention and Expansion International does not have a standard definition on its website. From the University of Minnesota Extension's point of view (Darger, 2014; Loveridge \& Morse, 1998): BRE visitation is an intentional process in which communities organize individuals to visit local businesses to demonstrate appreciation and to survey them about their concerns and needs. The data are analyzed in order to respond both to individual business concerns as well as to address systemic issues affecting the community's prospects for keeping and developing the businesses already existing in their community.

Organized BRE programs developed from a recognition of the vital importance of local businesses in an economy (Morse, 1990). BRE programs allow communities to address individual business issues while also providing insights into the concerns of the broader business community. Communities working in a systematic fashion to address business concerns can generate positive externalities like an entrepreneurial culture (Loehr, Streier, \& Darger, 20062008) or a strong business environment (Morse, 1990; Yamoah \& Darger, 2016). 
However, BRE programs cannot provide all the economic development activity that a community needs. For example, while a positive business climate developed through BRE efforts can help to attract new businesses, BRE itself is not designed to be an attraction strategy. Further, it does not provide an outside perspective on the prospects or relative attractiveness of doing business in the community.

In the 1990s, there were numerous states, land grant universities, and Canadian provinces promulgating BRE visitation programs. Although today there are fewer universities offering BRE expertise, the University of Minnesota Extension continues to engage deeply with communities to professionalize and optimize their BRE efforts.

The literature specific to the $B R \& E$ Strategies Program at the University of Minnesota will be briefly reviewed. The history, unique components, and approach will be explained. The bulk of the article is devoted to lessons learned in deep process evaluation as well as from the innovation of ripple effect mapping. In the end, a summary of Program innovations is provided and several suggestions are made for potential future research and evaluation.

\section{Literature review}

Existing literature about BRE visitation programs stands out from traditional literature in the economic development field, most notably because it integrates concepts from theories described in business, economics, and community development literature. The interdisciplinary nature of the community economic development field has shaped research efforts. Early research focused on the development of successful visitation programs while more recent research has shifted focus towards evaluating the outcomes and impacts of such programs.

The core of existing BRE research started to develop in the 1980s, culminating in 1990 with the publication of The Retention and Expansion of Existing Businesses (Morse, 1990). This 
book was instrumental in establishing a framework for BRE visitation programs, and the framework has been widely adopted and practiced by many in the economic development field (Lenzi, 1991; Warner \& Zheng, 2011.

Several authors in the BRE book edited by Morse (1990) examined the impact that BRE programming had during the implementation phase. For example, McLaughlin examined observations by both program participants and non-participants during a program in Ohio during 1986-1987. The study asked how participants themselves define program effectiveness, and what factors they identify as enhancing or impeding effectiveness. This research found that the program enhanced and improved relationships amongst program participants. Further, business owners were impressed with the appreciation demonstrated to them by the community, and the process (particularly the "red flag" review of the survey data) improved the manner in which local policy decisions were made (McLaughlin, 1990).

Journal articles in the 1990s further shared lessons learned and best practices from several states. Multiple articles (Loveridge, Smith, \& Morse, 1991; Loveridge \& Smith, 1992; Smith, Morse, \& Lobao, 1992) report on various facets of successful BRE visitation programs culled from a survey of local coordinators in six states. The articles point to the strengths of BRE visitation programs including increased social capital and the development of relationships between businesses and community leaders

Allanach and Loveridge (1998) completed an assessment of BRE visitation program communities and analyzed characteristics by success and geography. The authors examined 95 counties in four states that had completed a visitation program using trained volunteers and compared them to counties that had not undertaken a program. The communities that elected to do BRE programs were found to have higher unemployment rates and a greater reliance on the 
manufacturing sector when they entered the BRE program. Also, successful programs used a broad and diverse task force to develop and implement recommendations. Counties that had a development professional assigned to the visitation and that identified the individuals responsible for implementing projects were more successful. Notably, many visitation programs had a tendency to collapse during the implementation phase. Counties visiting the most businesses (i.e. over 70 businesses) had the poorest outcomes in implementation, suggesting that expending too much effort in the data collection phase could be counter-productive.

In the years since 2000, however, blind reviewed literature in traditional academic journals covering the topic of BRE visitation programs and their merits has become sparse. Nevertheless, the lack of new scholarly contributions does not seem to have been a detractor to this popular economic development practice (Warner \& Zheng, 2011).

A literature review conducted by the University of Minnesota Extension Center for Community Vitality in 2015 noted that the relative lack of research after 2000 may be due to a few reasons: 1. the lack of a scholarly contribution should not be surprising because BRE is usually implemented very locally, 2. evaluating the process and results is relatively difficult, and 3. the number of businesses typically interviewed (between 30-100) is relatively small resulting in limited sample sizes for analysis (Tremper, 2015). Recognizing the inherent interdisciplinary nature of the field might help encourage future research collaborations from interested academics and practitioner-scholars.

\section{History and impact of business retention and expansion at the University of Minnesota}

Since 1986, Business Retention and Expansion programming has become established widely as an active economic development activity (particularly in the US and Canada). States and 
provinces have assorted practices to help local businesses survive and grow which differ in approach and have varying levels of success (IEDC, 2016).

With its roots at The Ohio State University in the late 1980s, the University of Minnesota Extension has offered a visitation model (BR\&E Strategies Program, or the Program) since 1990 when it was established by George Morse. The Program's continuation to the time of this writing is evidence of its value to communities across the state.

There is no singular benchmark or metric used to gauge success of the Program. However, since 2011 the Program has consistently used ripple effect mapping to document outcomes and impact. Before that time case studies are the best source of evidence of Program effectiveness (Love, 1997; Loehr, Streier, \& Darger, 2006-2008). For example, former Extension educator Dorothy Rosemeier stated that "one hundred jobs were saved and over 100 additional businesses were created" because of a BRE initiative that helped retain and expand a key employer in Swift County, Minnesota (Love, 1997). In a study of nine community BREs (Bosma, 2007) a variety of successes were cited by participants; which included housing development for workforce, zoning changes in several communities, tax changes to address a resort owner's concerns, luncheons to provide information to businesses, community events, chamber of commerce reorganization, and hotel rooms added in one community. This is particularly notable as these nine communities were evaluated by Bosma because of an ostensible lack of success.

After a decade of experience with the model, Loveridge and Morse (1998) documented the Program methodology in a series of instructional booklets and videos. These booklets were designed to guide local development professionals or practitioner-scholars as they consider using the Program as well as when they kick off and implement a local BRE initiative. 


\section{Unique characteristics of the Business Retention and Expansion Strategies Program}

The University of Minnesota's BR\&E Strategies Program today is founded on the successful BRE practices described by Loveridge and Morse (1998). This section provides key details on the Program 26 years after its inception. The Program provides three services:

1. Fee-for-service applied BRE research and consulting to Minnesota communities

2. Instructor-mediated BRE courses in online and face-to-face formats

3. Educational resources and examples on its website

The BR\&E Strategies Program approach is founded on three primary principles: community engagement, education, and the use of quality data gathered by volunteers. These principles, taken together, distinguish Minnesota's approach from other BRE programs.

A community that chooses to participate in $B R \& E$ Strategies Program actively engages with a broad-based set of individuals (residents, business leaders, other community stakeholders) throughout the project. This differs from other approaches, which often rely on one or two staff members, or a small group, to conduct BRE efforts. The emphasis on community engagement is embedded throughout the process. When a community embarks on a BRE initiative, the most important tasks are to form a leadership team and task force. The leadership team has four to five coordinators that drive the process throughout the two to three years of the initiative. The task force is responsible for multiple aspects of the program, including providing input into program design, conducting business visits, and selecting projects for implementation. Communities are required to complete an application to be accepted into the $B R \& E$ Strategies Program. The application leads the community to demonstrate that they can deliver the motivation, the volunteers, and the persistence to complete the program successfully. One criterion for acceptance into the Program is broad community representation on the task force. 
An educational focus is infused throughout the $B R \& E$ Strategies Program process. Education occurs at multiple levels during the engagement. On one level, the community is gaining insights into the needs and concerns of the business community. On another level, the community is developing critical community engagement skills and building social capital. This differs from BRE approaches where the knowledge gained from business visits is retained by only a few people or local staff. When knowledge is not diffused broadly, it is likely because educating the community is not an explicit goal in many other BRE models.

Finally, communities are encouraged to collect both quality and a large quantity of data. Business visits are conducted using a standardized interview guide to collect data. The interview guide has been vetted by experts in both survey design and BRE to ensure questions will capture reliable and valid data. Random sampling techniques are usually used, at least for much of the sample, to select the businesses to be visited. The collection of quality data is critical to ensure the community is discussing and reflecting upon a valid and robust analysis of the businesses.

The University of Minnesota Extension has engaged over 75 community BRE initiatives through its BR\&E Strategies Program since 1990. In recent years, two to three communities per year participated. In the early years of the Program (i.e. prior to 2000), a minimal fee was charged to communities ( $\$ 500$ to $\$ 2,500)$. Since then, the fees have ranged from $\$ 7,000$ to $\$ 15,000$ per community. This fee provides partial cost recovery for the Program staff. It further ensures the community is serious about the BRE effort. The lower end of the price range covers data tabulation, analysis, report writing, and retreat facilitation. Most of these services are provided offsite. On the higher end of the price range, most communities choose to also have Extension educators assist them with training, facilitation, and consulting in the community. A key feature here is that the Program staff view the process as a partnership with the community 
in co-discovering the issues and opportunities facing the community. Program staff offer objectivity and expertise. However, their intention is to create ownership by and capacity inside the community during and after the three big steps of the process.

There may have been slightly more of an emphasis on quantity of community BREs in the early years of the program (i.e. before 2004) versus slightly more of a quality orientation in the latter years. In the early years, the price of the program was much lower and the Extension educators guiding the communities typically did not have as much training or experience in community economic development. Neither of these factors necessarily means that the earlier BREs were lower quality, but it is worth noting. For analysis see Appendix 1.

Of the communities engaging in the Program, data for 42 Minnesota communities have been collected and compiled (Tremper, 2015). In total, volunteers visited 1,820 businesses in those 42 communities (Table 1). On average, each community visited 43 businesses, but this varies widely, as evidenced by the standard deviation of 21 . Factors affecting the number of business visits include the size of the community and the number of willing volunteer visitors. Under the program, visitors conduct interviews in teams of two. The total number of business visits is typically constrained by the number of visitors, as evidenced by the fact that the average number of businesses (43) visited is close to the average number of volunteers (39).

Rural communities (those not located in the seven-county Twin Cities metropolitan area) are more likely to participate in the program. Those communities account for $64 \%$ of all participants. However, communities in the Twin Cities metropolitan area also find value in the program with $36 \%$ of all participants coming from the metro. There has been a shift in the last six years. Prior to 2009, three-fourths of participating communities were classified as rural. Since $2009,62 \%$ of participating communities have been in the Twin Cities metro area. 
Table 1. Descriptive statistics for Minnesota's BR\&E Strategies Program.

\begin{tabular}{|l|r|}
\hline Business visits & 1,820 \\
\hline Total & 43 \\
\hline Average & 21 \\
\hline Standard deviation & \\
\hline & \\
Volunteers & 39 \\
\hline Average & 13 \\
\hline Standard deviation & \\
\hline & $64 \%$ \\
\hline Geography, 1993-2015 & $36 \%$ \\
\hline Rural & \\
\hline Twin Cities Metro & \\
\hline & \\
\hline Geography, 1993-2008 & $24 \%$ \\
\hline Rural & \\
\hline Twin Cities Metro & \\
\hline \multicolumn{2}{|c|}{$\mathrm{n}=42$ communities } \\
\hline Geography, 2009-2015 & $38 \%$ \\
\hline Rural & \\
\hline Twin Cities Metro & \\
\hline \multicolumn{2}{|l|}{} \\
\hline
\end{tabular}

In 2009, as a result of a deep program evaluation with nine communities, Program specialists reshaped the program design into a three-step process (Figure 1). The communities move through the three phases: research, prioritize, and implement. 


\section{Business Retention \& Expansion Strategies (BR\&E) Program}

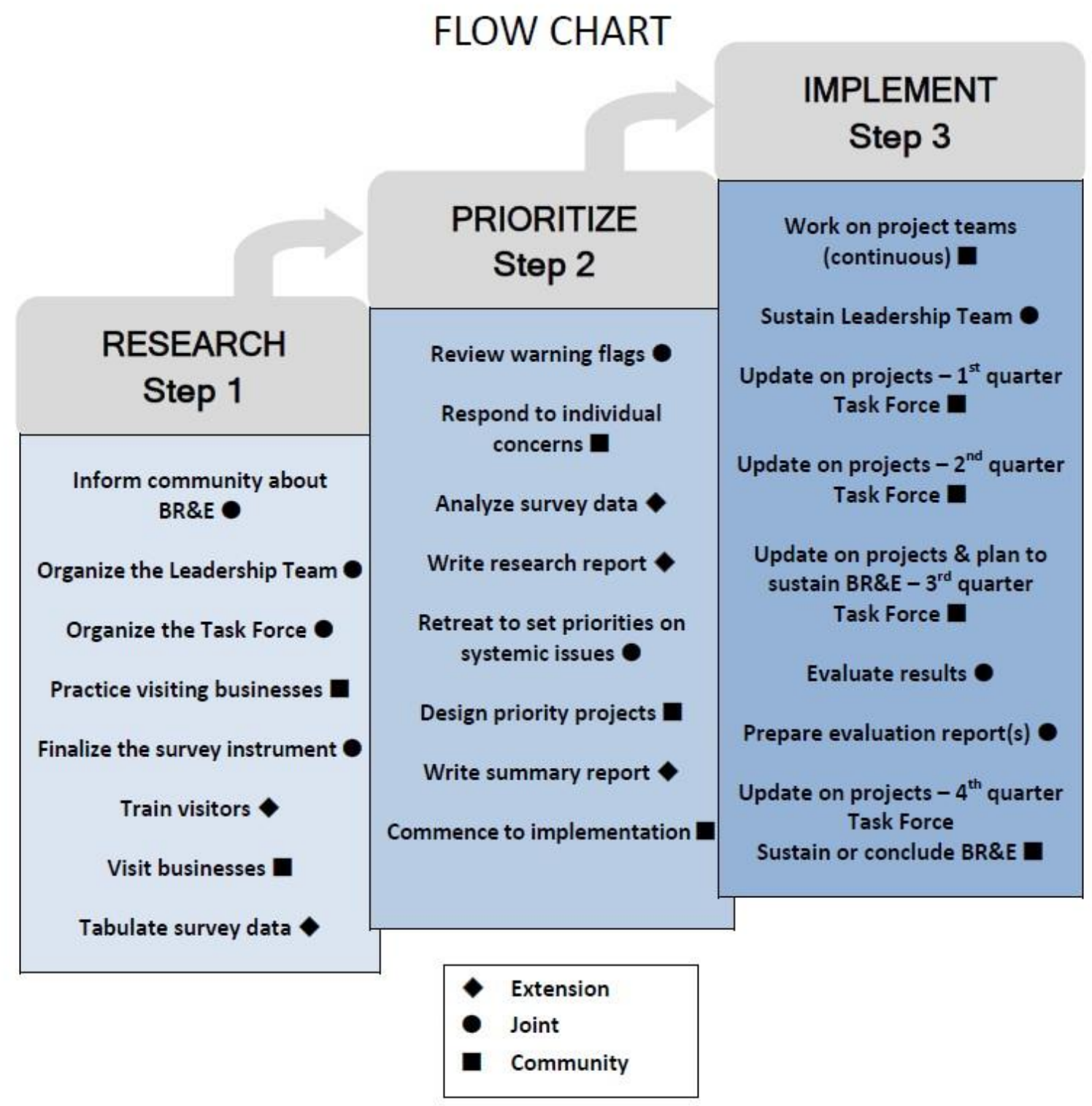

Figure 1. Minnesota’s BR\&E Strategies Program flowchart.

\section{Overview of the business retention and expansion process}

Communities begin the process with research. During RESEARCH Step 1 the community leadership team is learning about the entire process, forming a task force to complete the work, 
and designing the interview process (see Figure 1). This step culminates with the business visits. Teams of volunteer visitors interview local businesses and, using an interview guide, learn more about business concerns.

The team approach to visits diffuses the knowledge about business concerns more widely in the community. Each individual participant increases their personal knowledge and through their networks they can also increase the overall community knowledge. The engagement of community members on both a personal and group level provides opportunities for both education and motivation. Community members begin to fully understand the concerns of businesses. Since team members are learning of the concerns directly, they develop a personal stake in the outcome of the BR\&E Strategies Program.

When business visits are complete and the data tabulated, communities move into the PRIORITIZE Step 2 of the Program. In this phase, communities review the information learned from the business visits and form action plans based on their findings. Communities take action two ways. First, communities respond to individual business concerns. Second, communities address systemic issues facing some or all of the business community.

The primary emphasis of the BR\&E Strategies Program is on systemic issues affecting multiple businesses. As part of the Analysis task (Figure 1. under PRIORITIZE Step 2) an expert panel pores through the data over a three-hour session. Economic development and workforce experts from the University of Minnesota and other entities, alongside members of the community's leadership team, conduct a SWOT (strength, weaknesses, opportunities, and threats) analysis. Ultimately and most importantly, attendees suggest potential project ideas for the community to address themes or issues found in the business visit data. 
Following the campus research review meeting, the BR\&E Strategies Program staff prepare a research report. The research report identifies three to five major themes identified in the SWOT analysis. Ideas for community projects are listed under each theme. These potential project ideas come from sources that include the research review meeting, successful projects done in other communities, economic development literature, and other sources.

After Program staff deliver the research report, the task force convenes a retreat to prioritize the projects to implement in the community. At the retreat the task force explores the major themes identified in the research report and typically chooses three to five priority projects to implement. These priority projects are then featured in the summary report. The summary report provides a concise yet transparent narrative of the community-wide efforts that took place in the BRE initiative. It also heralds the community's priorities for action.

The final stage of the BR\&E Strategies Program is IMPLEMENT Step 3. During this step, communities implement their priority projects. The task force meets quarterly to ensure accountability and to offer mutual support and share successes through the media (traditional and social media) and events in order to sustain momentum and interest.

A recent innovation to the Program is using ripple effect mapping for evaluation (Darger, 2014; Kollock, Flage, Chazdon, Paine, \& Higgins, 2012). This method identifies outcomes stemming from a BRE initiative in the community. At an appropriate point after the task force retreat (typically 2-3 years), the Program staff and local BRE participants gather. Program staff facilitate a discussion of the observed implementation activities and community changes resulting either in whole or in part from the BRE initiative. These activities and changes are mapped using a computer mind mapping software. The result is a printable ripple effect map of results that is useful to both the community and the Program (see Darger, 2014 for details on this 
process). These results are then analyzed using the Community Capitals Framework (Emery \& Flora, 2006). The results are categorized into the seven "capitals" defined in the framework: built, human, social, civic, natural, financial, cultural, and an additional capital, health. See Table 2 for an example of the types of capitals that were affected by the BRE in Hugo, Minnesota. Ripple effect maps are too large to convey in this journal format, yet samples can be found online ${ }^{\mathrm{i}}$.

Table 2. Community capital "effects" found in a BRE ripple effect mapping in Hugo, Minnesota (2013). 
Table 2. Community capital effects from a BRE ripple effect map - Hugo, Minnesota

\begin{tabular}{|c|c|c|c|c|}
\hline $\begin{array}{l}\text { Category of } \\
\text { community program } \\
\text { effects }\end{array}$ & Definitions of categories & $\begin{array}{l}\text { Count of } \\
\text { reported } \\
\text { effects (out of } \\
\text { a total of } 41 \\
\text { effects } \\
\text { reported) * }\end{array}$ & $\begin{array}{l}\text { Percent of } \\
\text { reported } \\
\text { effects }\end{array}$ & Examples \\
\hline $\begin{array}{l}\text { Human capital effects } \\
\text { (knowledge and } \\
\text { behavior change) }\end{array}$ & $\begin{array}{l}\text { Changes in knowledge, attitudes, } \\
\text { or skills among community } \\
\text { members }\end{array}$ & 25 & $61.0 \%$ & $\begin{array}{l}\text { 1. Increased awareness of how many and } \\
\text { what kind of businesses are in the community } \\
2 \text {. City staffers got to know businesses }\end{array}$ \\
\hline Social capital effects & $\begin{array}{l}\text { Strengthened or expanded } \\
\text { connections among people, } \\
\text { groups and organizations }\end{array}$ & 12 & $29.3 \%$ & $\begin{array}{l}\text { 1. Hugo Business Association is gathering } \\
\text { more often with a purpose. } 2 \text {. City and } \\
\text { business groups are interacting more. }\end{array}$ \\
\hline $\begin{array}{l}\text { Civic effects (aka } \\
\text { political) }\end{array}$ & $\begin{array}{l}\text { Increased ability of communities } \\
\text { to access and mobilize public } \\
\text { resources }\end{array}$ & 20 & $48.8 \%$ & $\begin{array}{l}\text { 1. Created and filled a park and recreation } \\
\text { planning position } 2 \text {. City is still using a } \\
\text { business resource guide that was created in } \\
\text { the BR\&E program to assist businesses }\end{array}$ \\
\hline Financial effects & $\begin{array}{l}\text { Increased private and public } \\
\text { wealth that is invested in the } \\
\text { wellbeing of communities }\end{array}$ & 11 & $26.8 \%$ & $\begin{array}{l}\text { 1. Xcel Energy creating a training center with } \\
10 \text { jobs and lots of visiting trainees. } 2 \text {. } \\
\text { Providing promotion opportunities for } \\
\text { business } 3 \text {. City actively recruiting events to } \\
\text { be held in Hugo }\end{array}$ \\
\hline Built capital effects & $\begin{array}{l}\text { Improvement of structures and } \\
\text { infr astructures that contribute to } \\
\text { the wellbeing of communities }\end{array}$ & 7 & $17.1 \%$ & $\begin{array}{l}\text { Removed blighted build ings using 10-year, } \\
\text { interest-free loans with businesses }\end{array}$ \\
\hline
\end{tabular}

* Totals more than 41 because some effects were attributed to multiple community capitals 


\section{External evaluation leads to program changes}

The successes and outcomes of a community BRE initiative are usually apparent over time. The $B R \& E$ Strategies Program has substantial case study evidence of such successes in implementation (Loehr, Streier, \& Darger, 2006-2008). However, implementation results sometimes are unclear. Therefore, an external evaluator, Linda Bosma (2007), conducted a thorough program evaluation of the $B R \& E$ Strategies Program with nine communities that had unknown implementation outcomes (indented section below is a direct quote):

The evaluation was qualitative and sought to answer the following main questions:

1. About half of the BRE communities did not follow through on BRE plans; what happened in those communities?

2. Extension Service had a central assumption that involving community members in data collection and planning would create a commitment to (implementation) projects; to what extent is that assumption correct?

Information was gathered through 18 key informant interviews of participants from nine communities, document analysis of the nine BRE community reports, literature review of community organizing literature, organization of information into rubrics, and expert meetings with Extension Service staff to inform analysis, sample, and the final report. (Bosma, 2007, p. 1)

Bosma's findings were several fold: 
1. Even if communities did not implement their plans, the participants were still overwhelmingly positive about the BRE process including the relationships developed, the information gathered, and the opportunities for dialogue.

2. Some communities may not have intended to implement plans. The survey process itself was considered their notable achievement.

3. Sometimes the process was vulnerable to too much dependence on one person. If that person left, the process stalled. In at least a third of the communities, ownership and buy-in to the implementation process had not been developed.

4. Communities ultimately appreciated that community members themselves gather the BRE data first hand. They saw that the process creates trust with businesses and created more meaning for the participants.

5. The implementation process was not understood and appeared to have dwindled in most of the communities.

6. Staffing/volunteer resources were challenging:

Staff changes or departures were one challenge to success cited in the communities. Other barriers or challenges included limited time and energy among volunteers, the need for more people to get involved, and lack of ownership among community members. (Bosma, 2007, p. 3)

Bosma's insights on the community organizing aspects about BRE are worthy of note (Bosma, 2007). More germane, however, are the recommendations from her evaluation that led to four key changes in the $B R \& E$ Strategies Program. These changes are explained below. 


\section{Change 1. Emphasize plan implementation as the ultimate goal for business retention and expansion .}

Arguably, the most important change was to adjust the way the BR\&E Strategies Program is described and taught. Specifically, the ultimate goal for doing the Program was explicitly identified as plan implementation, not data gathering. Therefore, in 2009, about 20 years after the Program began, the flowchart was significantly redesigned. Among the three major BRE "steps" depicted in the diagram (see Figure 1), IMPLEMENT Step 3 is the highest and greatest step. The depiction of BRE in three steps suggests a stairway. Implementation is now depicted as the ultimate, most important, and most difficult step in a community BRE initiative. The community prepares itself for a quality implementation process with the information gathered in $R E S E A R C H$ Step 1 and the planning process shown in PRIORITIZE Step 2. As recommended by Allanach and Loveridge (1998), the community is coached to gear up for implementation action. To emphasize action, nouns on the old flowchart were replaced with action verbs to describe the three big steps as well as the individual tasks within each step. For instance, under PRIORITIZE Step 2, "research review meeting" was replaced with "analyze survey data." Finally, organize was acknowledged explicitly as an essential activity in RESEARCH Step 1 of the flow chart (see Figure 1).

\section{Change 2. Adjust the process for creating, vetting, and presenting potential project ideas.}

In the Program, potential project ideas are suggested to the community in the BRE research report, but it is up to the community to decide which ideas, including their own ideas, will become priority projects for implementation. The Program has a tradition of "crowd-sourcing"

(i.e. soliciting ideas, insights, and feedback from a big group of informed people) the analysis of the BRE data. This occurs through the previously described campus research review meeting. 
The research report author for the BRE Strategies Program weaves the assorted potential project ideas from the campus research review into a themed chapter in the BRE research report. The ideas (typically 15 to 30 total) are grouped into three or four themes and used to stimulate the BRE task force at its retreat to set priorities for systemic action. Ideally, an assortment of vetted ideas from easy to difficult-to-implement are presented to the community.

In one of the BRE communities evaluated by Bosma, it appears an unfortunate project idea emerged from the campus research review meeting. Evidence indicates implementation failed because this project idea was not properly vetted. Its failure was not an abject failure because the project idea was clearly very ambitious. However, the opportunity cost may have been significant for the community in terms of squandered effort and momentum. Additionally, from the standpoint of a portfolio of priority projects, having one of the three community priorities fail may have diminished the prospects for the other two selected priorities.

The lesson learned was that multiple authors or editors should review the potential project ideas. The idea is not to eliminate all risky or difficult ideas but to vet them and provide useful information and context. Vetting in this context is defined not as feasibility analysis. Rather, vetting considers the merits of an idea based on the community's situation, its resources, and other factors. Simply put, does the idea possibly fit the community's ability and prospects, or is it a poor fit? The research report authors rely on their own knowledge and experience but also on the knowledge of subject matter experts for this vetting process. At its highest and best, the Program reflects back to the community the information from the community's BRE research that suggests actions, investments, and initiatives appropriate to the community's unique situation. See Appendix 2 for more discussion. 


\section{Change 3. Invest more time and facilitator resources in the creation and implementation of}

plans for the priority projects.

The BR\&E Strategies Program manuals have very little instruction about project implementation compared with detailed instructions on data gathering, team building, and training volunteers (Loveridge \& Morse, 1998). Likewise, in the previous BRE flowchart, project implementation was a small part at the end. In the redesigned process flowchart (see Figure 1) there is more emphasis on the subject of project planning and a great deal of emphasis on implementation. This change was a direct result of Bosma's evaluation results:

All were able to remember the priority project they were assigned to, but only some felt they had implemented any or part of their plan. Only one of the nine communities felt it had successfully implemented its plan and was still working on several of the strategies. Often, success was identified as completing the survey and not connected to implementation. (Bosma, 2007, p. 2)

Previously, the $B R \& E$ Strategies Program emphasized urgency in getting the community to move from the retreat within a few weeks to the community commencement meeting. The commencement is an event where the priority projects are presented to the community as a whole. The current expectation is that participants will complete a project design process before presenting the ideas to the community.

\section{Change 4. Carefully screen communities for broad-based leadership and task force teams.}

As mentioned, Bosma found that some community BREs had too much dependence on one person. This is something previously found in the formative years of the Program (Loveridge \& Smith, 1992), and it influenced the Program design as seen in the training manuals (Loveridge \& 
Morse, 1998). The Program design calls for a model of leadership where specific duties are distributed among four to five individuals on the BRE leadership team.

Despite the program's leadership team model, some communities defaulted to one person taking on the majority of duties. Thus there was not a fidelity to the model (O'Donnell, 2008). This is not a concern if the one or two-person coordinator team performs well, stays in the community, and stays healthy. Unfortunately, in some communities the solo coordinators left or became ill, and the BRE initiatives suffered from loss of momentum or, worse, halted all activity in their BRE initiative.

This finding by Bosma re-affirmed that the Program's application process is important and needs to be adhered to. Communities are required to complete an application in order to enter the Program. The other critical activity is to educate the community about the importance of following the Program model and how to do so.

\section{Recent BREs show increased project implementation rate}

Although there has not been an external program evaluation since Bosma, the authors have evidence (from client interviews and/or ripple effect mapping) to believe the incidence of low or no implementation results by communities has significantly decreased since 2007 . Nine community BREs from 1999 to 2006 were studied by Bosma because Program staff were not aware of implementation of priority projects in those communities. However, 11 other BREs during the same period reported significant project implementation. Implementation success is defined here as the accomplishment of a priority project. Since the types of priority projects vary widely across communities, and even within community BRE initiatives, the success standard used here is based on whether the person interviewed from the community deemed the project as accomplished. Program staff contacted BRE leaders from each of the communities (except the 
communities studied by Bosma) to find out which projects were wholly or partially accomplished (i.e. 50\%+).

Table 3 compares the implementation success rates between that time period and the period thereafter (see the figures in bold font). The success rates improved significantly across three metrics. Further, it appears that even better implementation rates are happening since the advent of the ripple effect mapping technique. These data were self-reported by the communities. Although they were not externally validated or audited, the authors believe they are accurate and the increases in attainment rates are attributable to program improvements. For further discussion of other possible factors affecting plan implementation, see Appendix 3.

Table 3. Analysis of BRE initiatives in Minnesota communities 1999-2016. 
Table 3. Analysis of BRE initiatives in Minnesota communities 1999-2016

\begin{tabular}{|c|c|c|c|c|}
\hline & \multicolumn{2}{|c|}{$\begin{array}{l}\text { A. } \\
\text { Initiatives that took place during the time period of } \\
\text { the Bosma evaluation* }\end{array}$} & $\begin{array}{c}\text { B. } \\
\text { Initiatives since } \\
\text { Bosma evaluation* }\end{array}$ & $\begin{array}{l}\text { C. } \\
\text { Initiatives since ripple } \\
\text { effect mapping began in } \\
2011^{*}\end{array}$ \\
\hline $\begin{array}{l}\text { Date range (when BRE communities } \\
\text { started their implementation) }\end{array}$ & \multicolumn{2}{|c|}{ 1999-2006 } & 2007-2016 & $2010-2016$ \\
\hline $\begin{array}{l}\text { \# of community BRE visitation } \\
\text { initiatives studied }\end{array}$ & \multicolumn{2}{|c|}{$\begin{array}{c}\mathrm{N}=20 \\
\mathrm{~N} 1=\mathrm{Bosma}=9, \mathrm{~N} 2=\text { other }=11\end{array}$} & $\mathrm{~N}=18$ & $\mathrm{~N}=12$ \\
\hline \# that participated in ripple mapping & \multicolumn{2}{|c|}{ Not applicable } & 6 & 6 \\
\hline $\begin{array}{l}\text { (Separation of column A into sub- } \\
\text { columns) }\end{array}$ & $\begin{array}{c}\text { A1. } \\
\mathrm{N} 1=\text { Bosma }=9\end{array}$ & $\begin{array}{c}\mathrm{A} 2 . \\
\mathrm{N} 2=\text { other }=11\end{array}$ & & \\
\hline \multirow{2}{*}{$\begin{array}{l}\text { \% of implementation projects } \\
\text { accomplished (average of } \\
\text { community averages) }\end{array}$} & N/A** & $63 \%$ & \multirow[t]{2}{*}{$60 \%$} & \multirow[t]{2}{*}{$74 \%$} \\
\hline & \multicolumn{2}{|c|}{ Overall Average $=\mathbf{3 5} \% * * *$} & & \\
\hline \multirow{2}{*}{$\begin{array}{l}\% \text { of communities that } \\
\text { accomplished } 50 \% \text { or more of their } \\
\text { priority projects (\% of BRE initiatives } \\
\text { studied) }\end{array}$} & $\mathrm{N} / \mathrm{A}^{* *}$ & $73 \%$ & \multirow{2}{*}{$56 \%$} & \multirow{2}{*}{$75 \%$} \\
\hline & \multicolumn{2}{|c|}{ Overall Average $=\mathbf{4 0} \% * * *$} & & \\
\hline \multirow{2}{*}{$\begin{array}{l}\text { \% of communities that } \\
\text { accomplished at least one priority } \\
\text { project }\end{array}$} & N/A** & $100 \%$ & \multirow[t]{2}{*}{$89 \%$} & \multirow[t]{2}{*}{$92 \%$} \\
\hline & \multicolumn{2}{|c|}{ Overall Average $=\mathbf{5 5} \% * * *$} & & \\
\hline
\end{tabular}

* Note that columns A. and B. are mutually exclusive. However, the B. and C. columns overlap. Ripple effect mapping began in 2011 based on BREs that started implementation as early as 2010.

** Individual community breakdown not available from Bosma sample (column A2). However, Bosma study found only 4 of 18 (22\%) BRE informants (9 communities with 2 informants each) reported even partial accomplishment success. Therefore, likely project accomplishment was $0 \%$ (or near $0 \%$ ) in the 9 communities. The numbers and percentages shown in column A2. are calculated for the 11 other communities that did BRE in the same time period and were known to be successful.

*** Average $=(0 \% * \mathrm{~N} 1)+($ average $* \mathrm{~N} 2) /(\mathrm{N} 1+\mathrm{N} 2)$. The first term assumes an average of $0 \%$ for the communities Bosma evaluated. The second term shows the average for the other communities. 


\section{Ripple effect mapping provides implementation outcomes}

As previously mentioned, the $B R \& E$ Strategies Program began using ripple effect mapping in 2011 to collect the outcomes and impacts of community BRE projects. This technique allows both the community and the University of Minnesota Extension to efficiently gain information that is useful in analyzing the returns on the investments of significant amounts of community and University effort invested in BRE. The product of the analysis is a diagram that displays the "ripples" emanating outward from a community BRE initiative.

Six community BREs were assessed since 2011 in ripple effect mapping sessions with community BRE participants and beneficiaries. One of these communities hosted separate ripple mapping sessions 2.5 years apart. Each of the six communities revealed significant outcomes as a result of their BRE initiatives.

Analysis of the six ripple effect maps reveal some overarching themes (Yamoah \& Darger, 2016). The ripple effect data were self-reported by Program participants and mapped but not corroborated by the Program staff. Also, these data were collected in person by Program staff, not independent evaluators. Five themes emerged from the analysis: 1. stronger relationships, 2. connecting and collaborating amongst community members, 3. information sharing and new ideas, 4. supporting businesses, and 5. tangible actions observed (Yamoah \& Darger, 2016).

\section{Stronger relationships}

Stronger relationships and communications were observed between businesses and city (or county) offices in each community. This resulted because of the business visits themselves as well as subsequent implementation activities and events. This was observed in changes in attitudes and increased awareness and appreciation for businesses. In an opposite direction, in 
some of the communities businesses started to realize that city officials were concerned about them. In turn, the businesses become more willing to reach out to the city for help and refer each other to the city for assistance. A final example was the increased trust between a large county seat city and smaller towns in a rural county.

\section{Connecting and collaborating amongst community members}

It takes a significant effort to connect individuals and organizations into the collaboration needed to participate in the $B R \& E$ Strategies Program. Dozens of volunteers and dozens of businesses are involved. Therefore, it is not surprising that the six communities continued this connection and collaboration into the implementation phase.

\section{Information sharing and new ideas}

Another significant theme observed in the $B R \& E$ Strategies Program in general is information sharing and new ideas. The ripple maps confirmed this general observation as this behavior was demonstrated across all six communities.

\section{Supporting businesses}

Most of the six communities engaged in new activities to support existing or emerging businesses. A few examples are particularly noteworthy. A series of workshops was held in one community to help existing businesses with the goal of helping businesses through transitions in ownership or leadership. This is timely as communities everywhere are facing the question of what will happen to businesses owned by baby boomers as they transition to retirement. Workforce is an increasingly important issue for business. One small town established a Career Exposition Fair to connect existing businesses with students in the high school for networking. This annual event was created to familiarize the students with local businesses, occupational information, and entrepreneurial opportunities in their own hometown. 


\section{Tangible actions observed}

Another theme observed across the communities is that of tangible action. These are things apparent to community members whether they are part of the BRE initiative or not. For example, one city realized through its BRE that the businesses wanted them to address aesthetic issues by taking down some of the old buildings downtown. Another example was a small town that used the BRE business interview results to help make the case for two major utility enhancements in their small town. Natural gas was provided for the first time. Fiber-to-the-home internet was created by the city. Neither of these utility enhancements was expected as an outcome when the community launched their BRE initiative.

\section{Discussion and future research}

Since 2000, Minnesota's BR\&E Strategies Program has initiated five notable efforts to improve the Program. Two of them were discussed above: the Bosma study of nine community BRE initiatives and the creation of a consistent evaluation rubric utilizing ripple effect mapping to analyze BRE efforts (Darger, 2014). There was not enough room to discuss the other three initiatives yet they are significant developments in the program. The first innovation was an experiment with focus group methods in order to accommodate communities that cannot or will not engage in BRE using volunteer visitors (Hill \& Darger, 2014). The second initiative involved consulting with key informants and stakeholders to increase participant engagement through improvements in report writing and facilitation. The third initiative was to amalgamate and organize 22 years of community BRE datasets onto an online benchmark database in order to enhance communities' ability to understand their own BRE data (Tremper, Paine, Darger, Tuck, $\&$ Thiede, 2015). The last three items will be covered in future articles when there is more evidence of outcomes and impacts. 
The $B R \& E$ Strategies Program is a mature resource for community economic development throughout Minnesota. Demand continues for this Program into its $27^{\text {th }}$ year. Is the demand attributable to it being an inherently effective and efficient BRE approach? Or is demand driven because Minnesota communities view BRE as an essential component of economic development? Would communities conduct business visits independently in the absence of the BR\&E Strategies Program? These questions have no clear answers. However, this article has provided evidence of increasing Program quality as measured by increased community implementation of the priority projects that were adopted in their BRE initiatives. Increasing quality is most likely a result of changes implemented because of program evaluation and development. However, other contributing factors are explored in Appendix 3. The thesis of this article is supported by the evidence; BRE can strengthen the economic and social fabrics of communities when led by a broad cross-section of community leaders and supported by educators who are familiar with BRE techniques.

$\mathrm{BRE}$ is an evolving practice that is widely used in economic development in the US (Warner \& Zheng, 2011), yet there is little published literature in recent years as to researchtested best practices. However, based on the evidence documented here, the authors are confident about two items. First, volunteer involvement in BRE can be effective in creating communitywide benefits when there is a deliberate focus on broad-based community engagement. Second, there are benefits to striving for both community development and economic development in BRE because it is about community improvement overall, not just jobs and economic impact.

Future research should continue to advance knowledge on the efficacy and importance of community-led BRE processes. Specifically, how does the community continue to keep connecting with its economic base? The economic development professional or other community 
development staff person is the ideal person to lead the BRE initiative. Yet it is important to research methods for broadening community involvement. This includes exploring the tradeoffs between professional staff doing everything versus engaging more broadly with the community to both spread the work and the economic development knowledge beyond the professional. Finally, it would be helpful to explore the implications of BRE program design for urban, suburban, and rural areas.

\section{References}

Allanach, C., \& Loveridge, S. (1998). An assessment of maximum-training business visitation programs. Economic Development Quarterly, 12(2), 125-136.

Bosma, L. (2007). From BR\&E theory to practice in Minnesota: Lessons learned from local community modifications in implementation. Retrieved from http://www.extension.umn.edu/community/business-retention/researchdevelopment/docs/Bosma-report.pdf

Darger, M. (2014). Capturing the ripples from community-driven business retention and expansion program. Journal of Extension, 52(2), Article 2TOT6. Retrieved from http://www.joe.org/joe/2014april/tt6.php

Emery, M., \& Flora, C.B. (2006). Spiraling-up: Mapping community transformation with community capitals framework. Community Development, 37(1), 19-35. doi:10.1080/15575330609490152

Helping Minnesota communities retain and expand their businesses. (2016). The program website for the University of Minnesota BR\&E Strategies Program. Extension Center for 
Community Vitality, University of Minnesota, St. Paul. Retrieved from http://www.bre.umn.edu

Hill, J., \& Darger, M. (2014). Using focus groups for business retention and expansion (BR\&E) at the community level: Detailed notes about the Columbus, Minnesota BR\&E Program. University of Minnesota Department of Applied Economics Staff paper P14-8. Retrieved from http://ageconsearch.umn.edu//handle/183432

IEDC (International Economic Development Council). (2016). BRE: 30 Years of Community Economic Impact. Conference workshop in Cleveland, Ohio.

Kollock, D., Flage, L., Chazdon, S., Paine, N., \& Higgins, L. (2012). Ripple effect mapping: A "radiant" way to capture program impacts. Journal of Extension, 50(5), Article 5TOT6. Retrieved from http://www.joe.org/joe/2012october/tt6.php

Lenzi, R.C. (1991). Business retention and expansion programs: A panoramic view. Economic Development Review, 9(1), 7-11.

Loehr, E., Streier, J., \& Darger, M. (2006-2008). Case studies (about BRE outcomes). Extension Center for Community Vitality, University of Minnesota, St. Paul. Retrieved from http://www.extension.umn.edu/community/business-retention/case-studies/\#case

Love, P. (1997). Building strong cities. There are many ways to generate new possibilities and opportunities for your community. If your plans are backed with more ambition than cash, perhaps you should consider a less expensive, more expansive approach. Minnesota Cities, 1997 (June/July), 11.

Loveridge, S., \& Morse, G.W. (1998). Implementing local business retention and expansion visitation programs, (a series of five educational booklets on BRE). College Station, Pennsylvania: Northeast Regional Center for Rural Development at Penn State 
University. Retrieved from http://www.extension.umn.edu/community/businessretention/strategies/resources-booklets/

Loveridge, S., \& Smith, T.R. (1992). Factors related to success in business retention and expansion programs. Community Development, 23(2), 66-78.

doi:10.1080/15575339209489931

Loveridge, S., Smith, T.R., \& Morse, G. (1991). What does it take to run a local business retention and expansion program? A six state survey. Economic Development Review, Winter, 12-15.

McLaughlin, R.T. (1990). Making connections through R\&E: An educator's case study. In G.W. Morse (Ed.), The Retention and Expansion of Existing Businesses (pp. 166-178). Ames, Iowa: Iowa State University Press.

Morse, G.W. (1990). (Ed.). The retention and expansion of existing businesses. Ames, Iowa: Iowa State University Press.

O'Donnell, C. (2008). Defining, conceptualizing, and measuring fidelity of implementation and its relationship to outcomes in $\mathrm{K}-12$ curriculum intervention research. Review of Educational Research 78(1), 33-84. doi:10.3102/0034654307313793

Smith, T.R., Morse, G.W., \& Lobao, L.M. (1992). Measuring impacts of business retention and expansion visitation programs. Community Development, 23(1), 123-143. doi:10.1080/15575339209489944

Tremper, J. (2015). (Unpublished). Literature review of BR\&E literature. Extension Center for Community Vitality, University of Minnesota, St. Paul.

Tremper, J., Paine, N., Darger, M., Tuck, B., \& Thiede, S., (2015). BR\&E benchmarks: Sharing more than 20 years of BR\&E interview data with the field of economic development. 
Extension Center for Community Vitality, University of Minnesota, St. Paul. Retrieved from http://www.extension.umn.edu/community/business-retention/researchdevelopment/benchmarks/

Warner, M., \& Zheng, L. (2011). Economic development strategies for recessionary times: Survey results from 2009. The ICMA Municipal Year Book 2011. Washington, D.C.: ICMA, 33-42. Retrieved from http://cms.mildredwarner.org/p/164

Yamoah, E., \& Darger, M. (2016). A narrative of the results of business retention and expansion (BR\&E) initiatives across Minnesota - based on six ripple effect maps of community BR\&Es. Extension Center for Community Vitality, University of Minnesota, St. Paul. Retrieved from http://www.extension.umn.edu/community/business-retention/researchdevelopment/docs/bre-results-in-six-communities.pdf

\section{Appendix 1. Quality vs. quantity of community BREs.}

The early years saw as many as seven community BREs in one year (1993) whereas the later years have had as few as one community (2005). Here are some likely reasons. First, the Program fees and application requirements were far lower in the early years thus there was a slightly lower barrier to entry. Second, the Extension context in Minnesota in those years was a classic combination of county-based educators delivering the Program with campus faculty providing the applied research services. The educators were bringing a new "technology" to their county and likely earning credit from local elected officials for the novelty of this technology transfer. For the tenure-track faculty (i.e. at the St. Paul campus) involved, they were conducting research on BRE efficacy while refining the $B R \& E$ Strategies Program model. In this context, compared to today, the incentives for the earlier Extension educators and faculty may have been slightly tilted more to quantity (i.e. $\mathrm{N}$ size) than to quality (i.e. long term outcomes). To be fair, 
this mild critique is offered by authors who have different incentives than the Program founders and the benefit of 20-20 hindsight. Explanation of the current Extension structure of regional educators is provided in Appendix 3.

\section{Appendix 2.}

This topic of vetting potential project ideas brings up two related concepts that are tangential but worth some discussion: single sector versus mixed sector BREs and feasibility analysis.

\section{Single sector vs. mixed sector samples.}

Mixed sector samples of businesses are much more commonly seen in the Minnesota BRE context than single sector outreach efforts. This can be explained in terms of both scale and pragmatism. If the size of a community doing BRE is 10,000 people, for example, the chances of a community of that size having a significant number of businesses from any single sector is quite low. Thus there is a practical reason for a community BRE team to reach across multiple sectors in order to attain a respectable number of business interviews. In the University of Minnesota Extension context, the minimum number of businesses to visit has traditionally been 30. In all but one mixed sector case that threshold minimum was achieved. Another reason for mixed sector samples is the practical aspect of being able to state that any business has a chance of being visited if a random sampling technique is included in the selection process.

Communities that chose to engage with a particular business sector (e.g. tourism, dairy, or manufacturing), tended to have either a larger geography or greater population density, or both. For instance, doing BRE at a county or multicounty scale is popular for agricultural and tourism BREs, whereas manufacturing focused initiatives have tended to occur in larger communities such as large suburbs or urban areas. Another aspect of these sectoral BREs is the advantage for the analyst in being able to go more deeply into the data with businesses that 
ostensibly have more in common than a more dispersed array of businesses as found in a mixed sector sample.

\section{Feasibility analysis}

The BR\&E Strategies Program research report writers are expected to attain project ideas from any source that is credible and pertinent to the data. As aforementioned, Bosma found this is not a perfect process in that some ideas are not screened effectively. It potentially could be made better by doing feasibility analysis on potential project ideas. However, the BR\&E Strategies Program has never done this. There are two reasons. First, the community itself is charged with deciding on the applicability of any suggested idea. Second, feasibility analysis is beyond the scope and resources of the Program. For both of these reasons, the Program also strongly resists using the word recommendation in its research reports so as not to unduly influence the selection of priority projects by the community.

Appendix 3. The increased success after the Bosma evaluation project in communities implementing BRE priorities presumably is largely attributable to the changes described above (i.e. changes 1-4). Yet there may be other factors at work. One notable factor is the change in the University of Minnesota Extension educator network that occurred in 2004. Before 2004 the only local Program staff were educators with part-time community development duties in various county Extension offices or some nonemployees who took the Program's course and provided BRE consulting to communities (Program website, 2016). These county-based staff, for the most part, facilitated the BRE in the communities. In addition, Extension educators with no community development expertise (e.g. youth development or agricultural educators) also facilitated the Program in some communities, but only in two communities since 1999. Since that time, the only educators (besides the Program director in St. Paul) to facilitate BRE are full-time 
regional (i.e. multicounty) educators specializing in community development. Each educator has a master's degrees in a related field. Fourteen of the eighteen community BREs since 2006 have been assisted by one of these full-time community development educators. In contrast, only one of the communities from the Bosma study period had a full-time community development educator assisting them.

In addition there are a few other factors worth mentioning. First, since 2009 the Program has used specialized professional report writers for its BRE reports. Second, since late 2010, the Program director no longer had the distraction of also serving as an Extension administrator (i.e. Program Leader for Community Economics). Third, continuing investment in BRE research and educational improvements by the University of Minnesota Extension is significant. For instance, a professional video was created in 2009, a major new website created in 2011-2012, and new online, hybrid, and face-to-face BRE courses were created in 2012-2016.

i Ripple effect mapping image examples are available at http://blog-ripple-effectmapping.extension.umn.edu/p/image-examples.html 